\title{
Electrical Modification of Combustion and the Affect of Electrode Geometry on the Field Produced
}

\author{
Timothy J. C. Dolmansley, ${ }^{1,2}$ Christopher W. Wilson, ${ }^{1}$ and David A. Stone ${ }^{3}$ \\ ${ }^{1}$ Department of Mechanical Engineering, The University of Sheffield, Mappin Building, Mappin Street, Sheffield1 3JD, UK \\ ${ }^{2}$ Department of Mechanical Engineering, The University of Sheffield, Unit 2 Crown Works Industrial Estate, Rotherham Road, \\ Beighton S20 1AH, UK \\ ${ }^{3}$ Department of Electrical and Electronic Engineering, The University of Sheffield, Mappin Building, Mappin Street, \\ Sheffield1 3JD, UK
}

Correspondence should be addressed to Timothy J. C. Dolmansley, t.dolmansley@shef.ac.uk

Received 11 March 2011; Accepted 26 May 2011

Academic Editor: Zeki Ayag

Copyright (c) 2011 Timothy J. C. Dolmansley et al. This is an open access article distributed under the Creative Commons Attribution License, which permits unrestricted use, distribution, and reproduction in any medium, provided the original work is properly cited.

\begin{abstract}
There has been extensive work to show how electric fields can influence combustion. However, many different set ups are used. This work shows how different set ups produce different field strengths and that the field is not always uniformly distributed. The field strength is modelled using Ansys Maxwell. The type of material used is discussed and the set up of apparatus. It is recommended to use parallel plates for experimentation. Parallel plates produce the most uniform field this allow's it's influence to be directly investigated and related to the field strength.
\end{abstract}

\section{Introduction}

Ions are created as part of hydrocarbon combustion [1]. These ions can be moved and excited when subjected to an external electric field [2]. The effects of this can be used to extinguish flames [3-6], to increase the flammability limits [5-15], to reduce the pollutants emitted $[8,9,16-28]$, effect the temperature (by entraining air) $[9,17,29]$, modify the burning velocity $[7,13,30]$, or to increase/decrease the heating to surfaces surrounding a flame. The effects have been well documented; however, the results are sometimes contradictory. For example, it is unclear whether an electric field can be used to change the burning velocity. Jaggers and Von Engel found that this was possible [7] but this is contradictory to other reports by Bowser and Weinberg [31] and also Jaggers et al. [32]. One of the reasons for this could be that the experimental set-up was not the same. Different electrode geometries will produce different electric fields.

Although the exact affect of an electric field has not been quantified, it is clear that it does have an effect (see all of the above references). This effect is related to the field strength.

In other areas of research the affect of electrode geometry has been studied; see Christopoulos for an overview [33].
Programs have been developed to model the electric field produced by different electrode geometries, for example, Maxwell [34] and FEMM [35]. The aim of this report is to use these programs to model the affect of electrode geometry on the field produced. This report also aims to recommend an electrode geometry that produces a uniform field, so that the combustion modifications can be directly related to a field strength. The results of this study can also be used to identify electrode geometries where the field is intensified around a flame so that the voltage required to modify the flame is less; however, this is beyond the scope of the present study. Physical measurement of the field is also problematic as the measuring probe distorts the field [36].

It is also not currently possible to model the electric field with the flame present. This is because the flame is conductive of electricity (see Lawton and Weinberg [37]) and will modify the field. However, the field is also having an effect on the flame and changing its shape. This coupling of the flame and field requires combination of a computational fluid dynamics (CFD) program, a chemical kinetic mechanism which includes ions and an electric field modelling program. There has been some work to couple chemical kinetics with CFD (see fluent [38]) but the chemical mechanisms 
are not complex enough to cope with the introduction of ionic species. There is not even a full chemical kinetic mechanism that includes ions for modelling in programs such as CHEMKIN [39, 40]. There has been some work to develop one (see [41-44]) but is not currently good enough to predict the exact concentrations of ions and where they are formed in the flame.

Current work to predict what the electric field looks like and how the electrode geometry changes the type of field produced is contained in [37] P480, [45] P508, and [46, 47]. However, this work was conducted before the development of modern modelling programs such as Maxwell [33] and FEMM [35] which can offer a greater insight into how the field looks.

1.1. Boundary Conditions Used to Model the Field. The modelling program computes the static electric field arising from potential differences and charge distributions. To do this it relies on solving the first of Maxwell's equations: Gauss' law. Gauss' law can be stated in several ways but it is the differential form that the modelling program uses:

$$
\nabla \cdot\left(\varepsilon_{r} \varepsilon_{0} \nabla \phi(x, y)\right)=-\rho,
$$

where

(i) $\nabla$ is the del operator. This expresses the divergence. So the divergence of the vector $v(x, y, z)=v_{x} \mathbf{i}+v_{y} \mathbf{j}+$ $v_{z} \mathbf{k}$ is $\operatorname{div} \underline{\vec{v}}=\frac{\delta v_{x}}{\delta x}+\frac{\delta v_{y}}{\delta y}+\frac{\delta v_{z}}{\delta z}=\nabla \cdot v$,

(ii) $\phi(x, y)$ is the electric potential and $\varepsilon_{r}$ is the relative permittivity. This is set in the modelling process,

(iii) $\varepsilon_{0}$ is the permittivity of free space, $8.854 \times 10^{-12}$ $\mathrm{Fm}^{-1}$ (Farads per metre),

(iv) $\rho$ is the charge density.

The program solves (1) for the potential $(\phi(x, y))$ of the finite element mesh. It then automatically computes the electric field and flux density using the equations. As part of the iteration process, the mesh in areas of high error is refined (in this case by $15 \%$ ).

The following settings will be used to try to make the results comparable to each other. All the electrodes are a distance of $60 \mathrm{~mm}$ apart and have a potential of $+10 \mathrm{kV}$ facing $0 \mathrm{~V}$ (ground). Unless stated the upper electrode is the one at high voltage (also known as EHT for Extremely High Tension). This is not the voltage used by many of the researchers. The main reason for conducting this modelling was to compare the types of field produced by different geometries to identify the best type for this study's application. To include the different voltages and distances would make the results very difficult to compare; so as far a possible the voltages and distances between electrodes have been kept the same.

Virtually all the models have been created using a rotational symmetry and the results mirrored (using a graphical processor, not the modelling program) to show a crosssection through the centre of the field. This was considered to give the best visual representation of the model. There have been a few instances where rotational symmetry was not suitable to use (set-up numbers 9 and 11 in Table 1).

Some of the researchers have used a metal mesh as one of the electrodes rather than a solid plate. It is not possible to model this in 2D and to produce a 3D model overcomplicates the problem. Meshes have therefore been modelled as a solid brass plate.

The voltages were applied to the electrodes using a sheet source applied to the outside of the conductor (either $0 \mathrm{~V}$ or $10,000 \mathrm{~V})$. It was chosen to apply the boundary in this manner so that the voltages did not interfere with the rotational symmetry boundary condition (or the outer boundary) when they overlapped. It is also a good representation of the theory that the modelling program is based on. This requires that the model is in equilibrium. Gauss' law states that the charge in a combustor rests on the surface when in equilibrium so that it can be as far apart as possible. It also states that because charge is free to move in a conductor, then if the conductor is in equilibrium, then there cannot be a field in the conductor and the flux entering/leaving a conductor must be at $90^{\circ}$ or the charge would experience an unbalanced force and move (meaning it is not in equilibrium).

The experimental set-up should for practical reasons be conducted in a Faraday cage. This provides a safety feature from the high voltages and also shields the equipment from any other electrical interference. The modelling has been setup to reflect this set-up. The boundary was set a significant distance away from the area of interest so that inconsistencies at the boundary did not affect the solution in the area of interest (between the electrodes). The affect of increasing the distance of the boundary from the electrodes can be seen in Figure 1.

Figure 1 shows that if the Faraday cage (earthed) is too close to the electrodes, then the field will be significantly altered. All the simulations in the remainder of this report show the perfect case of a boundary that is set at infinity.

To better analyse the results the field strength $0.2 \mathrm{~mm}$ above the bottom electrode can be plotted for all of the Faraday cage positions shown in Figure 1. The results of this are shown in Figure 2. The horizontal red line represents the balloon boundary condition where the Faraday cage is an infinite distance away.

Figure 2 shows that for practical situations the affect does not seem to be greatly altered once the Faraday cage is over $300 \mathrm{~mm}$ away from the electrodes. All the experiments in this report have therefore been conducted in a faraday cage that is over $300 \mathrm{~mm}$ away from the apparatus.

1.2. Program Used. There are several programs available. Both of the programs used in this report are freely available to download on the internet; so an interested reader may try modelling themselves. These are Maxwell [33] and FEMM [35]. We have an example of the field produced by parallel plates for both Maxwell and FEMM.

As you can see clearly from Figures 3 and 4 FEMM and Maxwell produce very similar results. Therefore only Maxwell will be used to produce the rest of the results in this report. 
TABLE 1: Type of electrodes used in the literature and the field they produce.

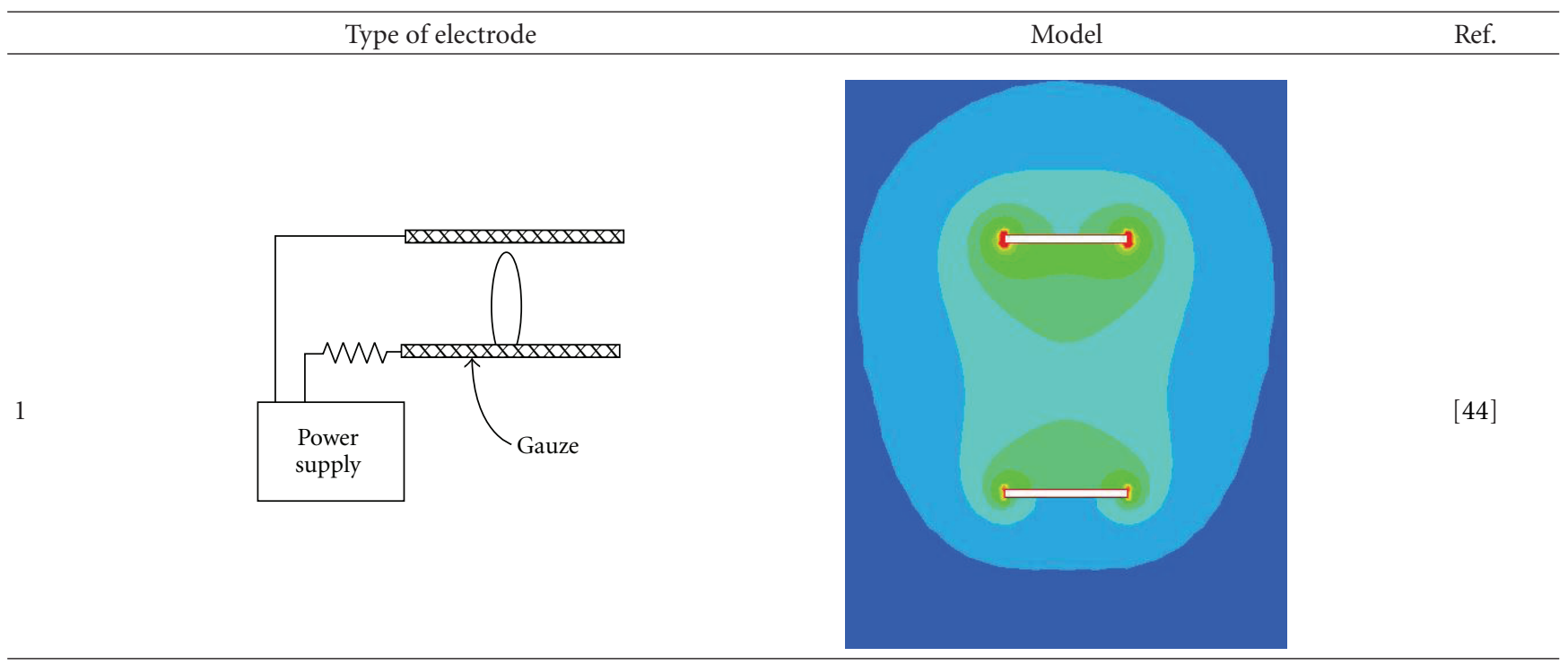

2

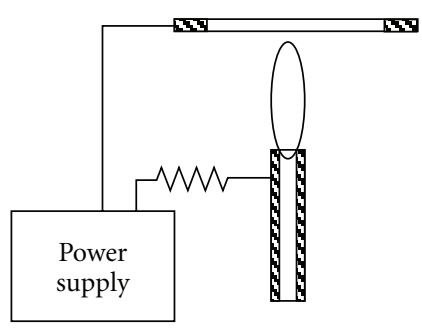

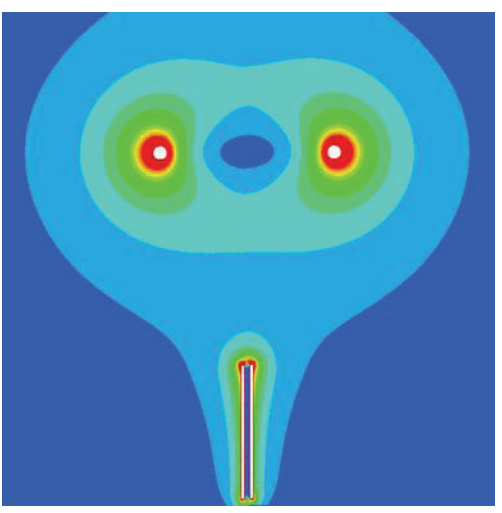

$[1,4,6,8,11$,

$12,45,54,58$ 59]

3

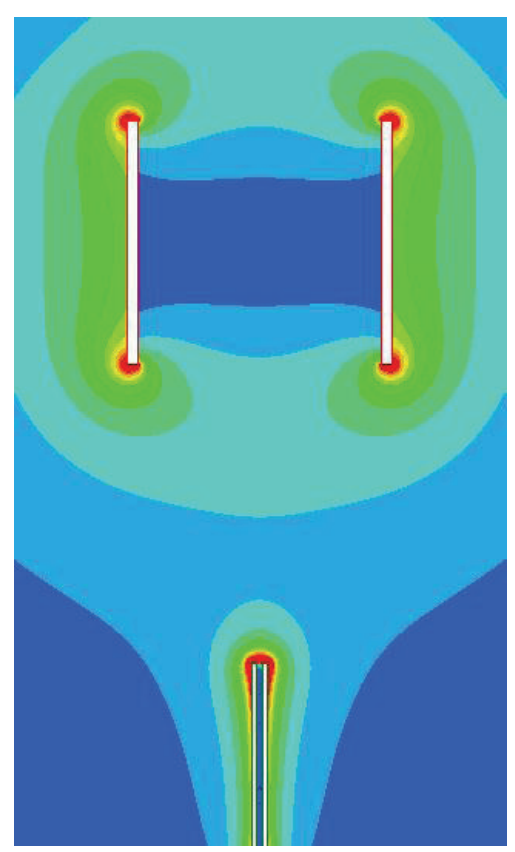

Solid Tube

$[30,58,60-$ 62]

Mesh Tube

$[4,63,64]$ 
Table 1: Continued.

Type of electrode

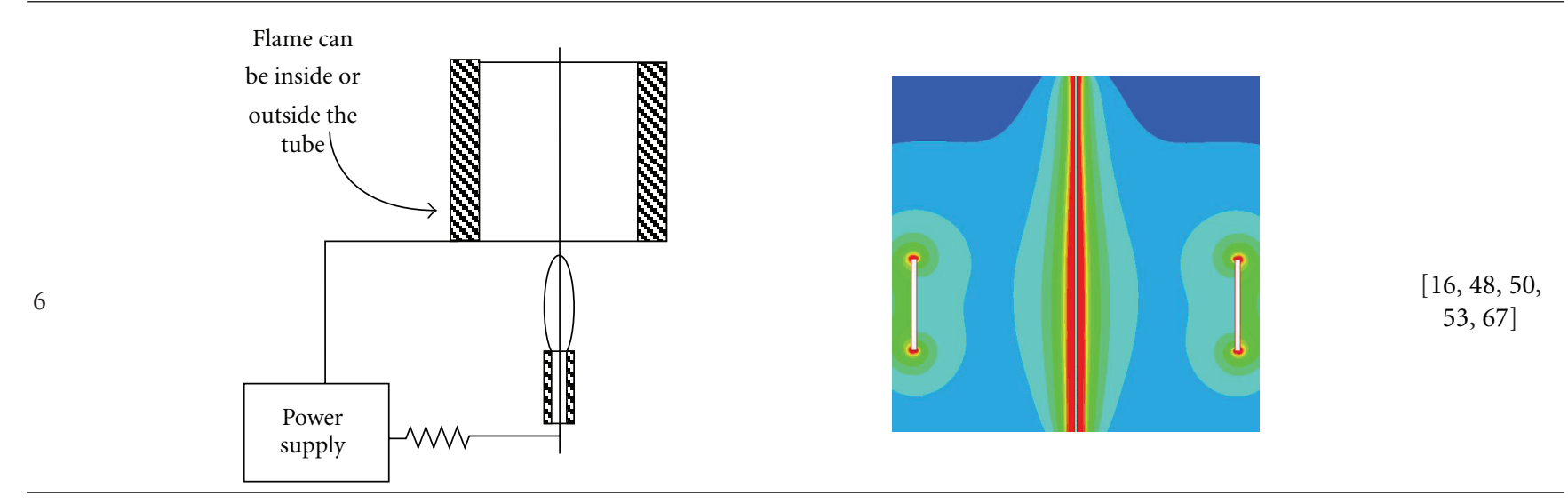

7
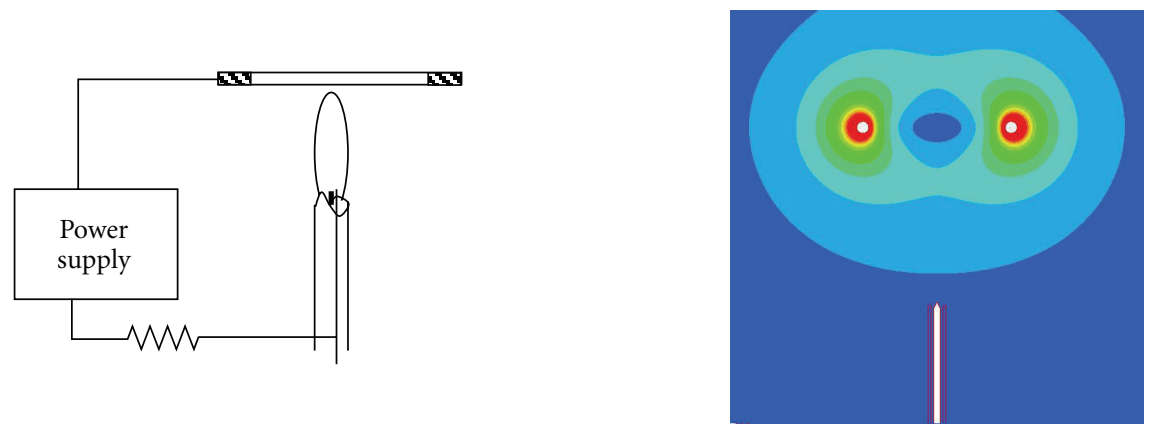

[45]
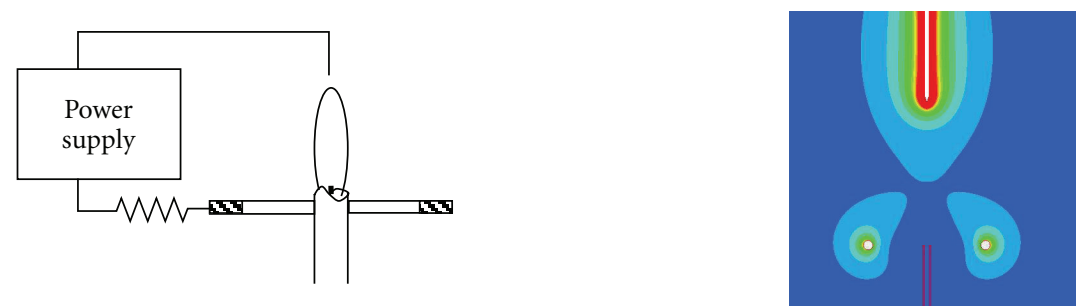
TABle 1: Continued.

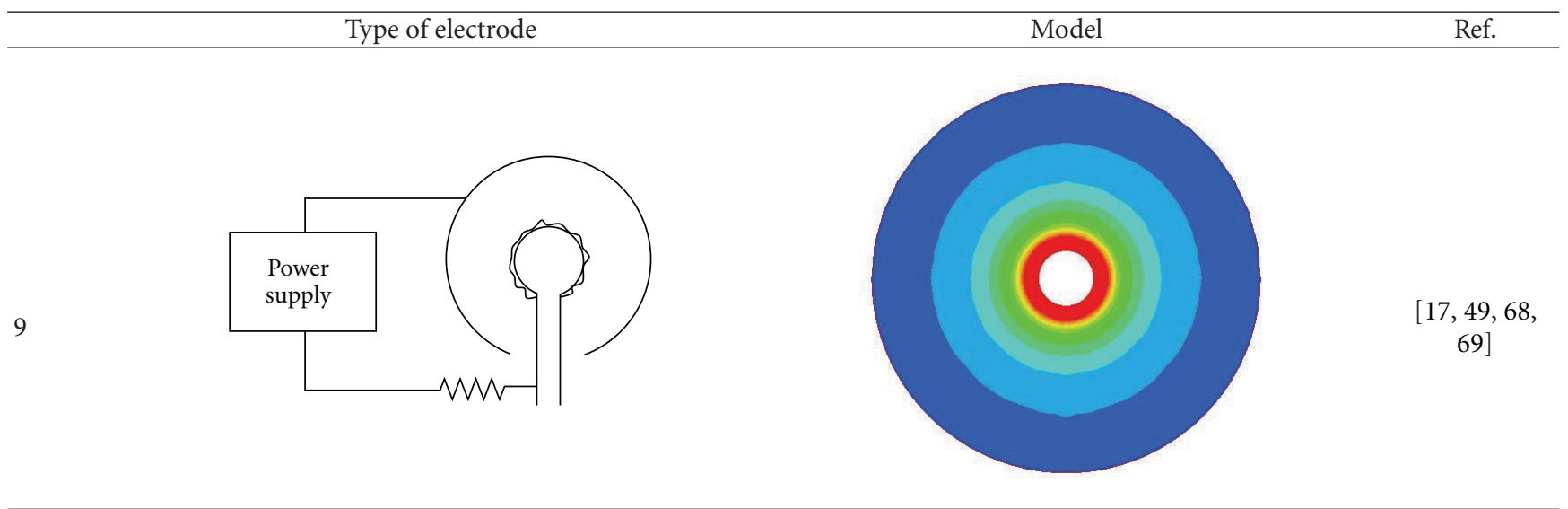

10
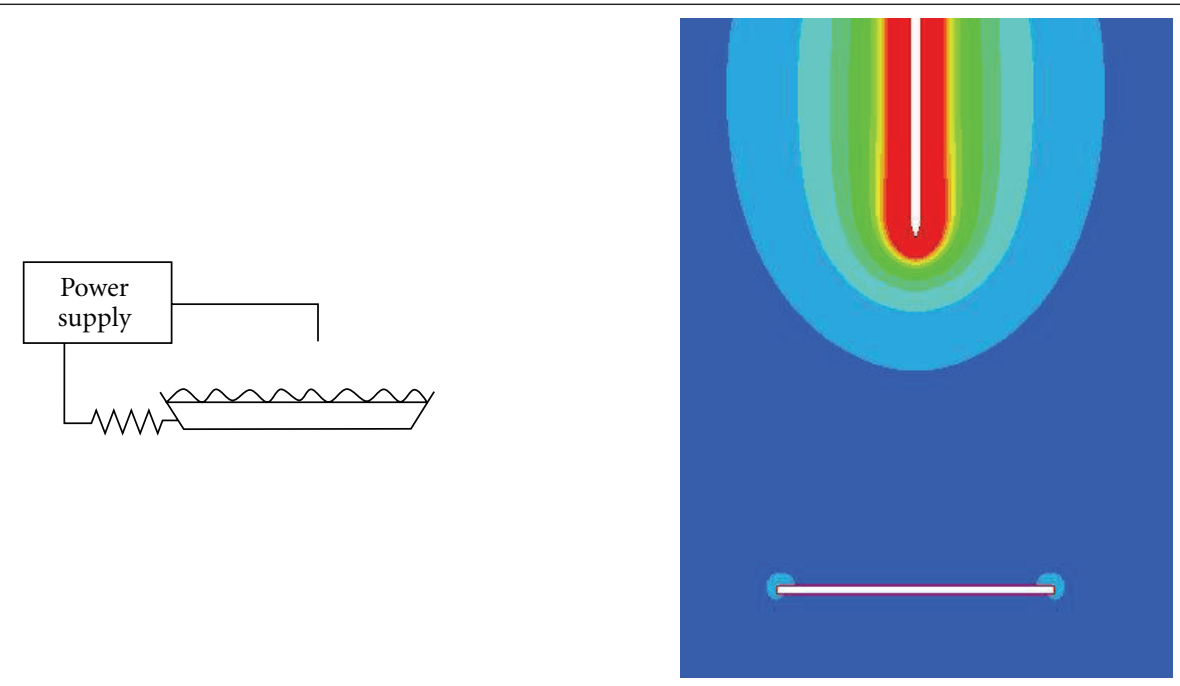

[3]

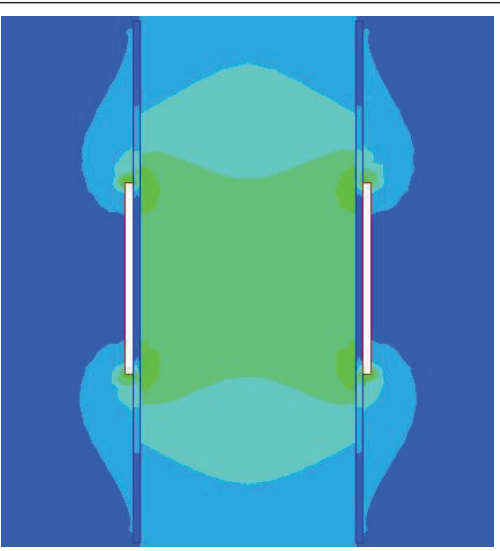

$[7,70]$

11
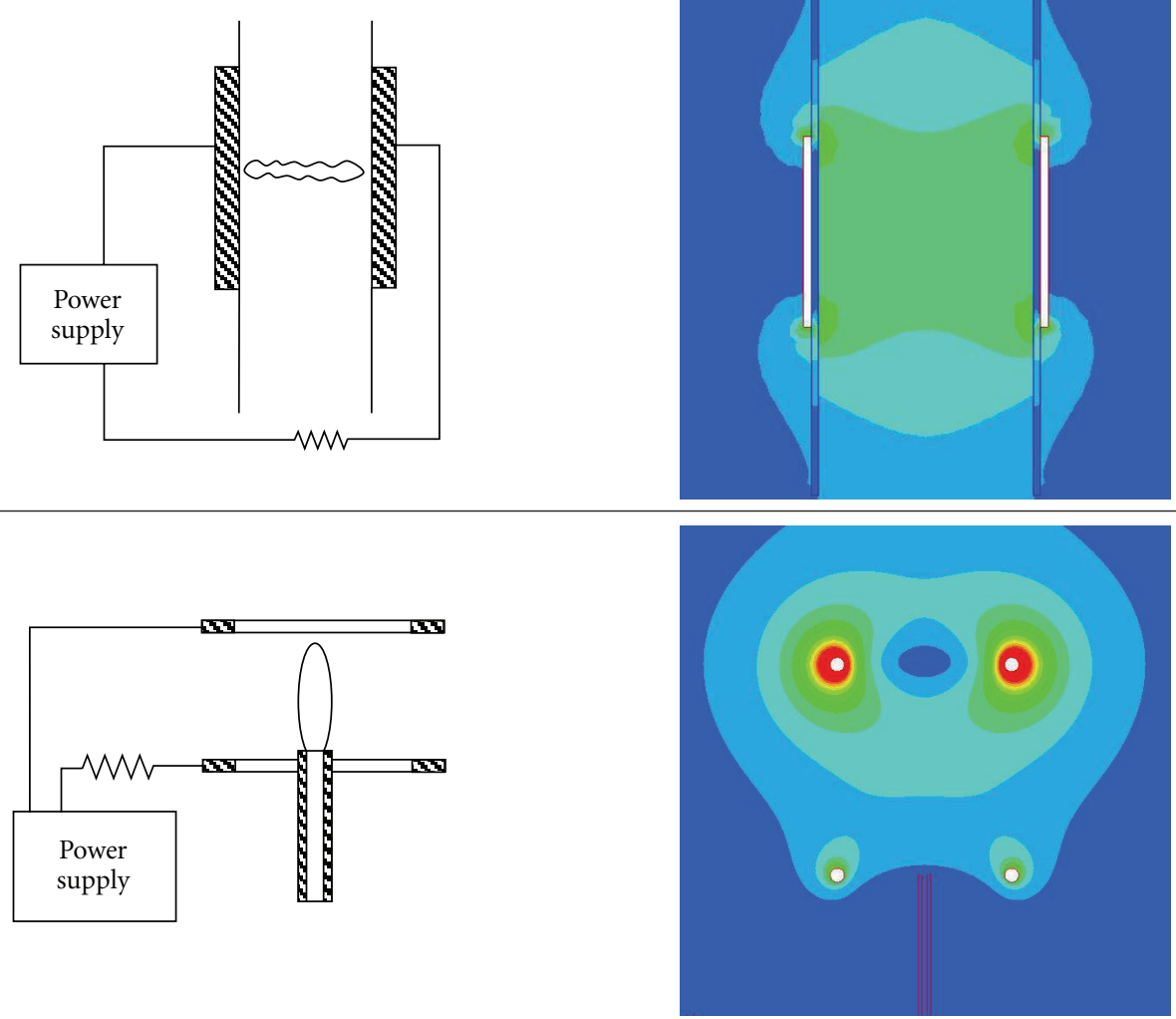

[16] 
Table 1: Continued.
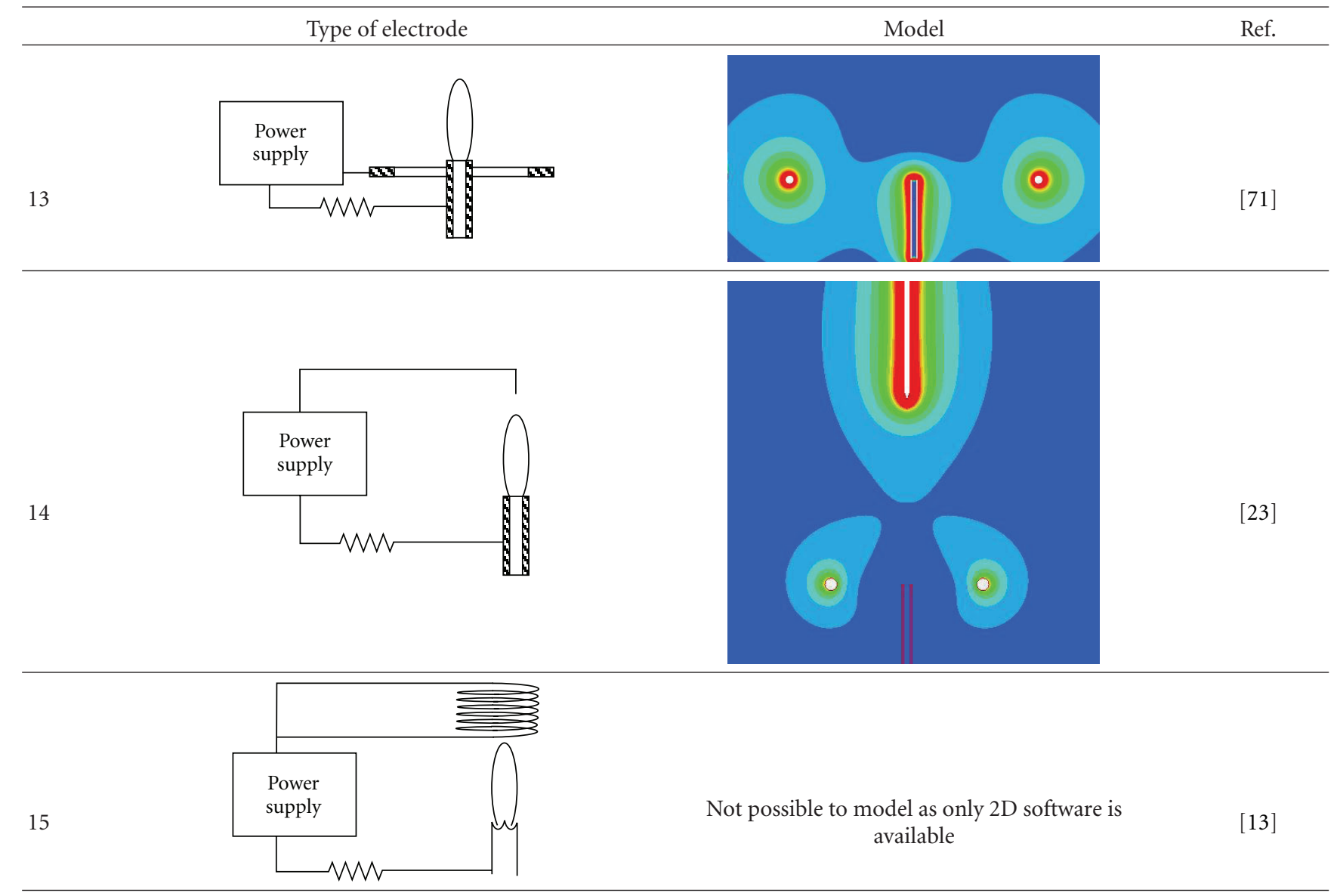

16

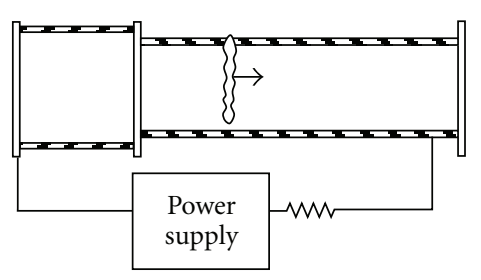

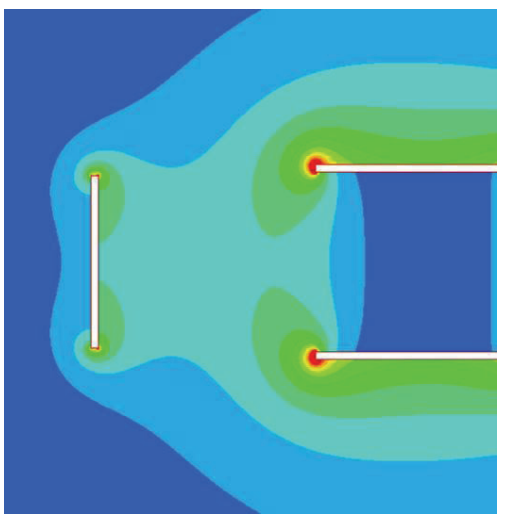

[71, 72]

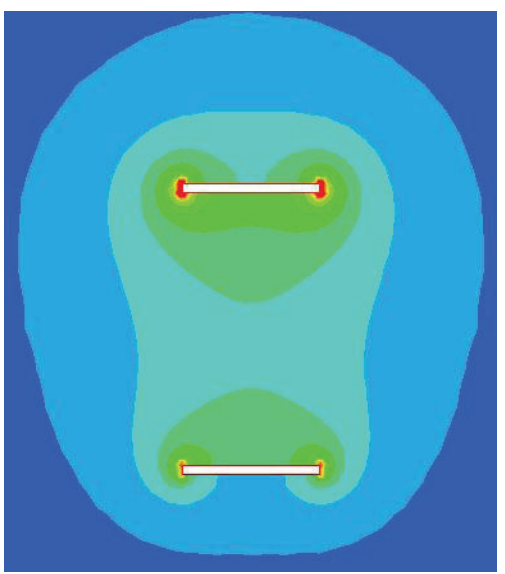

$[10,18,60$,

$65,66,73,74]$ 
TABLE 1: Continued.

Type of electrode

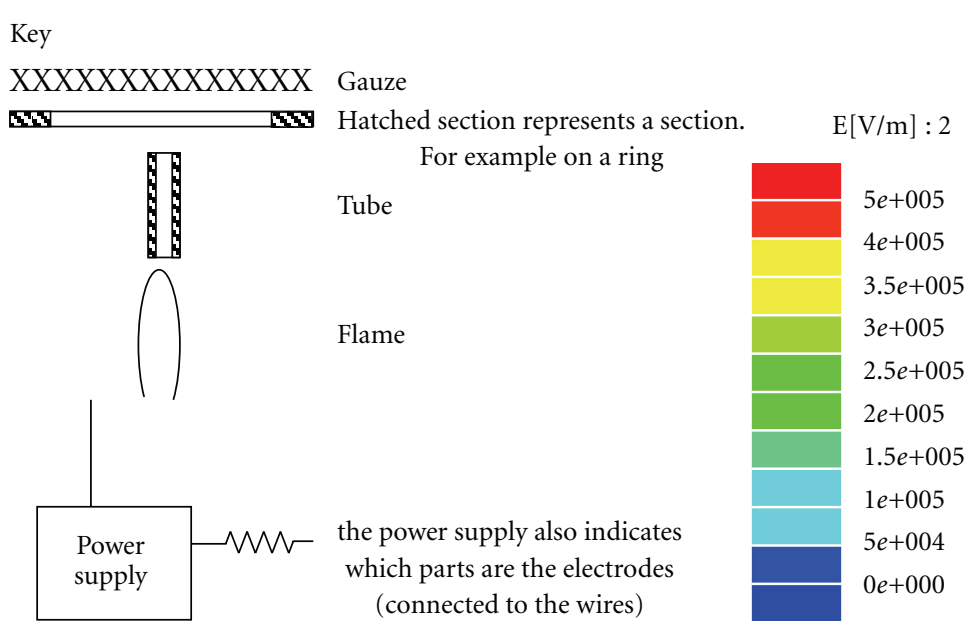

\section{Electrodes Used and the Field Produced}

Many of the effects are attributed to the aerodynamic affects caused by the ionic wind $[3,5,6,10,11,13,31,44,48-54]$. Therefore as the ionic wind is dependant on the orientation of the electrodes, this orientation is very significant. Also, if the field is not uniform, then the ionic wind will not be produced uniformly across the field. This effect could be used to magnify the affect in certain areas once the effects are properly understood. However, the diversity of apparatus tends to make understanding this topic more difficult as the results cannot be compared.

Currently a full schematic for ionic reactions is not currently available; however, there has been extensive work conducted to try and create a full model by Pedersen [41], Pedersen and Brown [42], Hu et al. [44, 55], Yuan et al. [17], Saito et al. [20], Jones et al. [56], and Smook et al. [57].

In some papers, particularly the older ones, the type and orientation of the electrodes is not even stated; so the conclusions drawn could be very unreliable. Here in after is a table to show the reader the scale of the problem and demonstrate the wide variety of experimental apparatus used(Table 1 ).

The results show that there are several field generation methods that provide an even field with little variation $(1,16$, 17). Most notably there are several fields that do not produce a field at all in the flame region (numbers 7, 8, 10, and 14). Consequently, the results from these tests may therefore not provide reliable results.
The results can be more easily compared if the field strength is plotted against the distance from the burner exit (Figure 5). All the results are plotted along a vertical line from the burner mouth to the upper electrode at $60 \mathrm{~mm}$, along the axis of symmetry. Only number 6 cannot be plotted in this way as there is a wire acting as the ground electrode along the axis of symmetry. The most uniform fields should appear as a flat horizontal line of the highest possible field strength. Large variations as mentioned previously are undesirable in this case.

The results cannot all be plotted on the same scale as the peaks for the wire and ring reach $3500 \mathrm{MV}$ but the main field strengths do not generally exceed 1.8 MV (see Figure 5). Therefore only the largest peak would be seen on a graph which plots this peak and the other apparatus would not even show on the bottom of the graph. Therefore the top of the peaks has been missed off the top of the graphs to show the main area of interest not the peak field strength (Figures 5 and 6).

Clearly the most uniform fields also have the lowest maximum value of field strength (Figure 6). Numbers 1, 11 , and 16 produce the most uniform fields. However the largest field strength possible is also desirable. This means that numbers 1 and 11 are better than 16. The centre line of 16 shows an even plot but the field is less uniform towards the outside of the flame region. The direction of the field is also important as this will govern the direction of the ionic wind. Number 1 produces a field that will create an ionic 


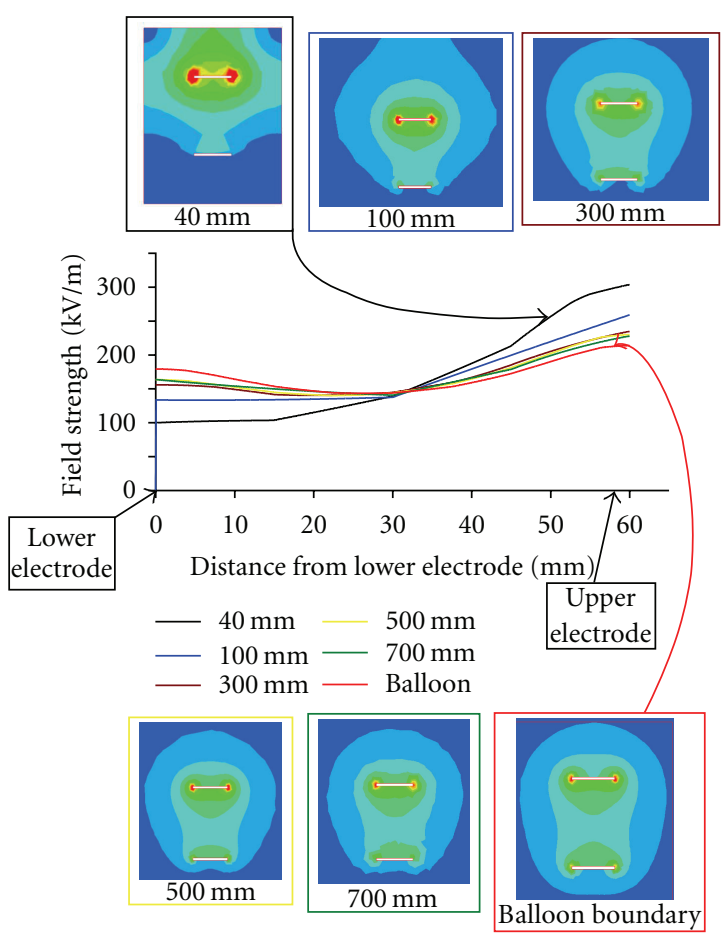

FIGURE 1: Graph to show the affect of altering the distance between the Faraday cage and the electrodes.

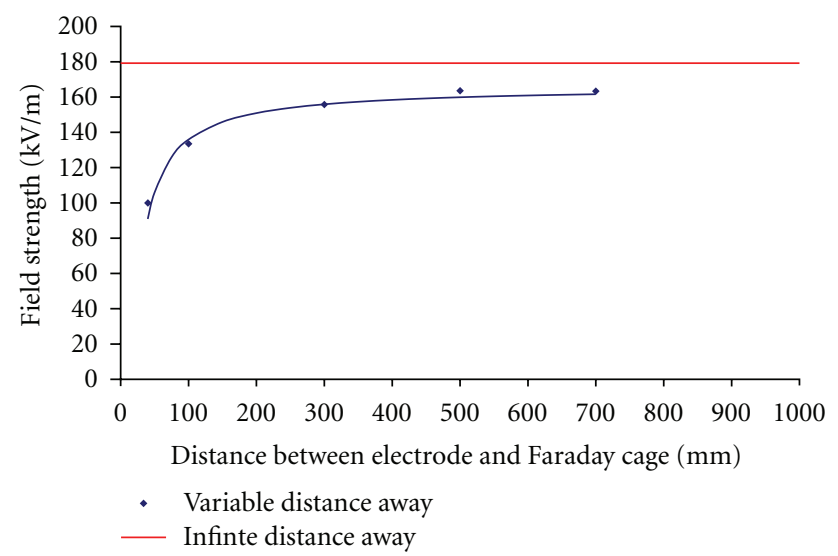

FIGURE 2: Graph to show the affect on the field strength $(0.2 \mathrm{~mm}$ above the bottom electrode) by altering the distance between faraday cage and apparatus.

wind parallel to the flow whereas number 11 produces an ionic wind that is transverse to the flow.

The figures above also indicate how the choice of geometry can increase the maximum field strength by over 6 orders of magnitude from the estimated average field strength (shown approximately by numbers 1,11 , and 16). This maximum in the flame region could create a much greater ionic wind affect. The problem is that this ionic wind will significantly move the flame and may pull it out of the region where the affect is greatest. The results are very useful for those using AC or pulsed fields where the ionic wind is not significant. The affects observed in these fields could be greatly multiplied by choosing an electrode that concentrates
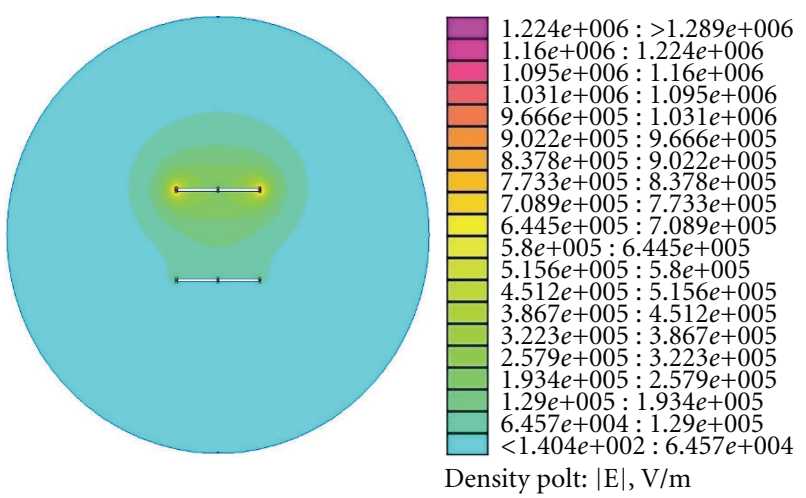

FIGURE 3: Field produced by FEMM balloon boundary.
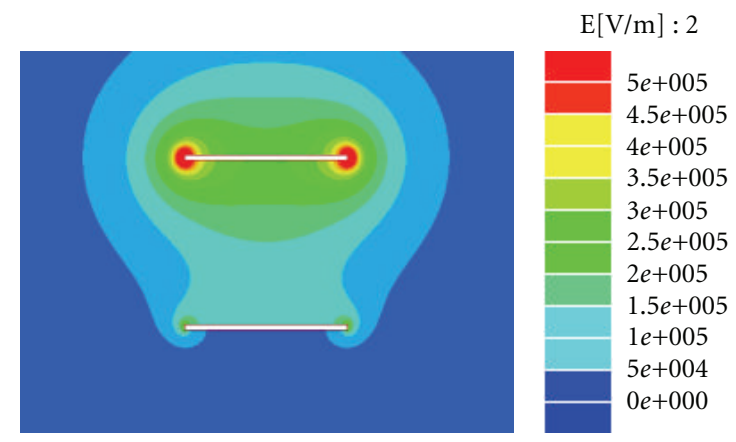

FIGURE 4: Field produced by Maxwell with a balloon boundary.

the field into the flame region. This can be considered to be the first $30 \mathrm{~mm}$ from the burner mouth for the majority experiments in the literature.

Figure 8 shows that it is very difficult to increase the field strength over the entire flame region. The only significant enhancement on the parallel plates (vertical 1 or transverse 11 ) is those experiments conducted in a microgravity environment (number 9). This apparatus, however, is very expensive to use and not easily available. It is also not suitable for standard combustion systems.

The ring and burner apparatus (number 2) also gives much higher field strengths for the first $10 \mathrm{~mm}$ but then drops below the more uniform fields and even reaches 0 at $25 \mathrm{~mm}$ above the burner. The presence of the flame may however increase this region.

2.1. Affect of the Upper Electrode. There was some speculation in the literature $[6,11]$ as to whether the geometry of the upper electrode made much difference to the field setup. It was found experimentally that it did not cause any measurable difference to the flame modifications caused. The models of the two cases are shown in Figure 9.

The results show similar trends near to the burner mouth but the plate produces a more uniform field at the top. This change near to the upper electrode is unlikely to affect the experimental results significantly as the flame would tend to be positioned below this area. With the plate the maximum field strength is lower $\left(4.58 \times 10^{6}\right.$ with plate and $7.89 \times 10^{6}$ with a ring). 


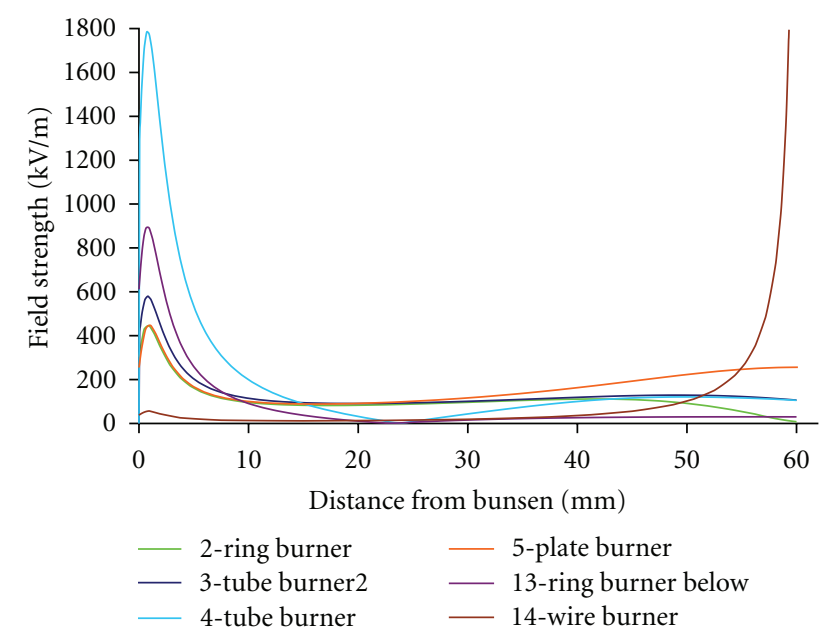

FIGURE 5: Field strength versus distance from the burner for medium field strengths.

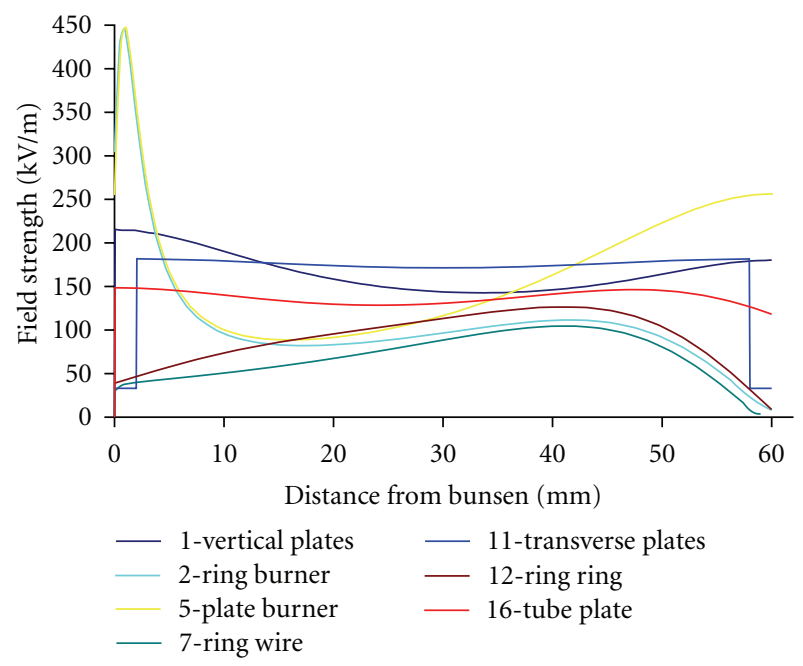

FIGURE 6: Field strength versus distance from the burner for small field strengths.

The results for a comparison between a tube and a plate as the upper electrodes show similar results to the previous comparison (see Figure 10).

As before the lower section near the burner is very similar. However, in the vicinity of the upper electrode the field between the two sets of apparatus is very different. The results from this do show a slight expansion of the higher field strength region close to the burner mouth. These results can be plotted on a graph to show the field strength along the centre line of the model (Figure 11).

The experimental data tested a ring (number 2) and a mesh (number 5) as the upper electrodes. The modelling results (Figure 11) show that these two experimental apparatus produce almost identical fields.

The large peak of number 14 has been ignored for this discussion as a corona will be formed in this region. The experimental data also did not include the affect of coronas $[6,11]$.

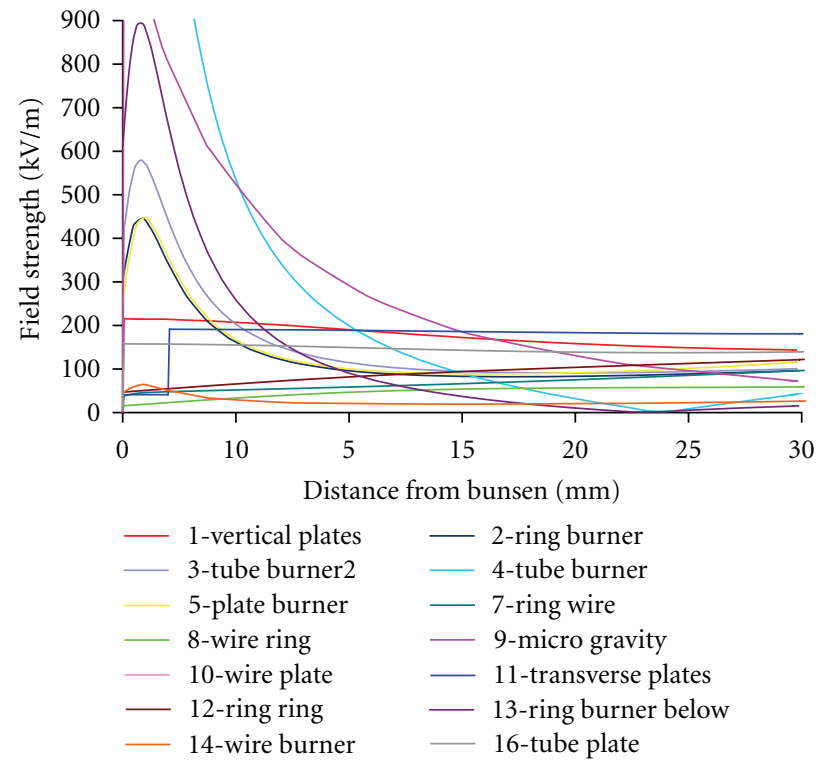

Figure 7: Enlargement of flame region.

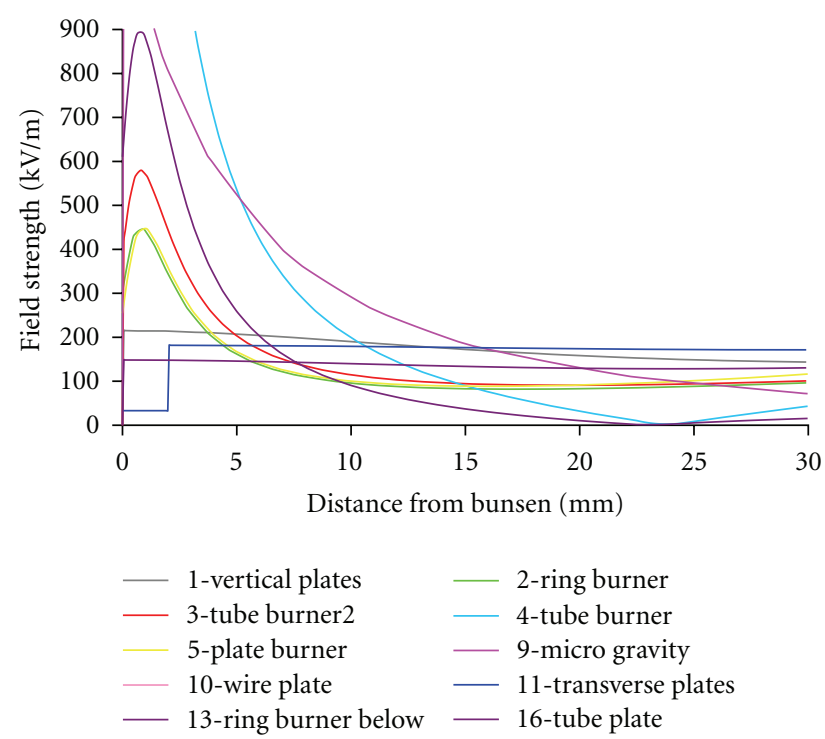

FigURE 8: Enlargement of flame region with selected data removed.

The largest peak (number 4) was not also included in the experimental data. Although Figure 11 shows that the peak voltage varies by an order of magnitude, this is only in the first 5 to $10 \mathrm{~mm}$. The presence of the flame will also change; this meaning that there is no way to plot this as the flame covers a significant part of the plotted axis.

In conclusion, the modelling correlates with the experimental results. The field in the combustion region is not significantly affected by different types of upper electrode but mainly by the lower electrode. This is logical as the major factor in the local production of a field is the geometry of the electrode nearest to it. In the case of a metal burner being used as an electrode, the field in the vicinity of the flame will be mainly governed by the burner geometry not the upper electrode, as long as no corona is formed. This does not, 
$\mathrm{E}[\mathrm{V} / \mathrm{m}]: 2$

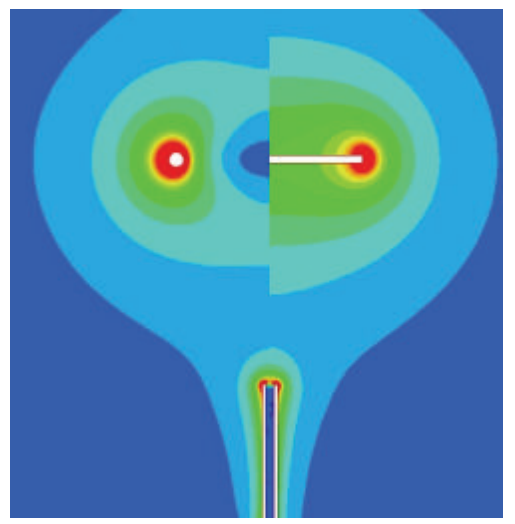

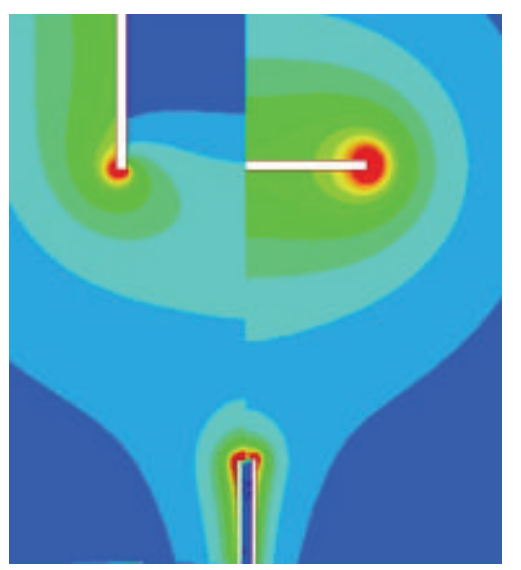

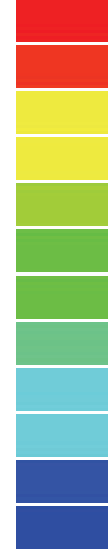

$5 e+005$

$4.5 e+005$

$4 e+005$

$3.5 e+005$

$3 e+005$

$2.5 e+005$

$2 e+005$

$1.5 e+005$

$1 e+005$

$5 e+004$

$0 e+000$

FIGURE 10: Comparison of tube and plate.

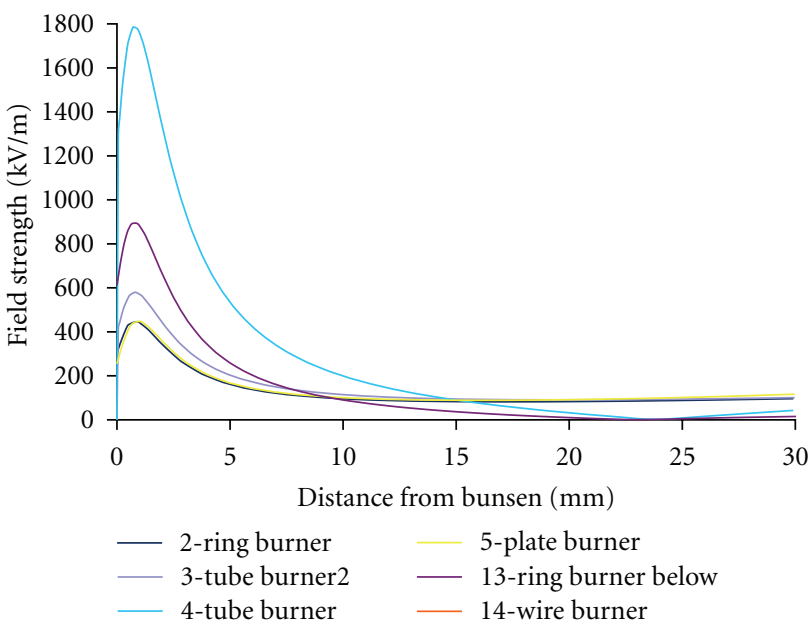

FIGURE 11: Affect of variations to the upper electrode.
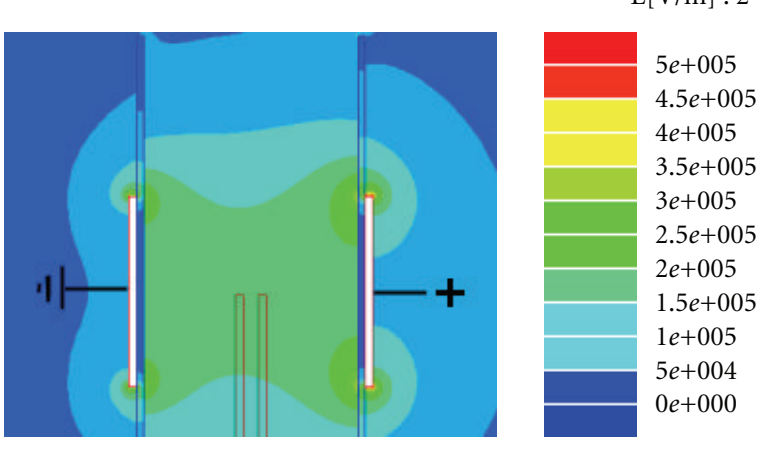

FIGURE 12: Ceramic burner.

$\mathrm{E}[\mathrm{V} / \mathrm{m}]: 2$
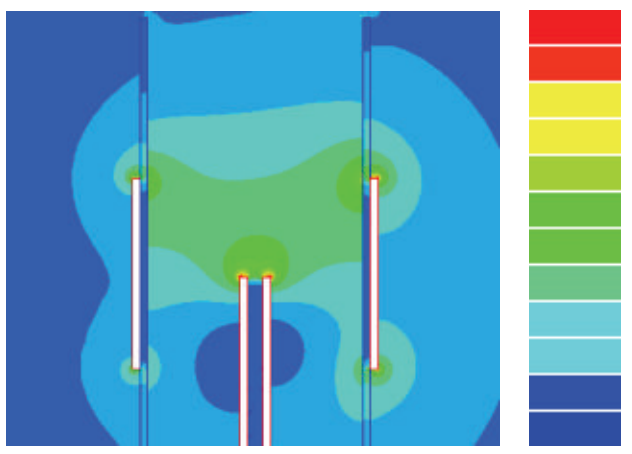

$5 e+005$

$4.5 e+005$

$4 e+005$

$3.5 e+005$

$3 e+005$

$2.5 e+005$

$2 e+005$

$1.5 e+005$

$1 e+005$

$5 e+004$

$0 e+000$

however, mean that it is suitable to use any type of geometry as any imperfections in the burner mouth could lead to local changes in the field. It is far better to try and achieve a more uniform field that is easier to reproduce between researchers.

2.2. Burner Material. In preliminary experiments with fields perpendicular to the flame, it was found that a metal burner body could shield a flame from some of the affects that would otherwise be observed. Figure 12 is a model of a transverse field with a nonmetallic burner. In Figures 13 and 14 the significant change to the field can be observed with a metal burner instead of a ceramic one.

The metal burner created a high field strength spike from the sharp corners. It also shields the incoming gasses from the field around the burner mouth. This seems consistent with the experimental data. It was attempted to extinguish the flame but extinction was not possible (even at very high field strengths) as the flame decreased in size until it was only present at the very tip of the burner. At this point the burner shielded the flame from the field, as shown previously.

2.3. Cutting a Hole in the Plate. It would be expected that geometries that are smoother will produce a more uniform field. In the literature the most recommended set-up to produce a uniform field is parallel plates (see number 1). The field only varies by $10-20 \%$, which is small compared to many of the other fields that vary by $100 \%$ over the flame 
$\mathrm{E}[\mathrm{V} / \mathrm{m}]: 2$
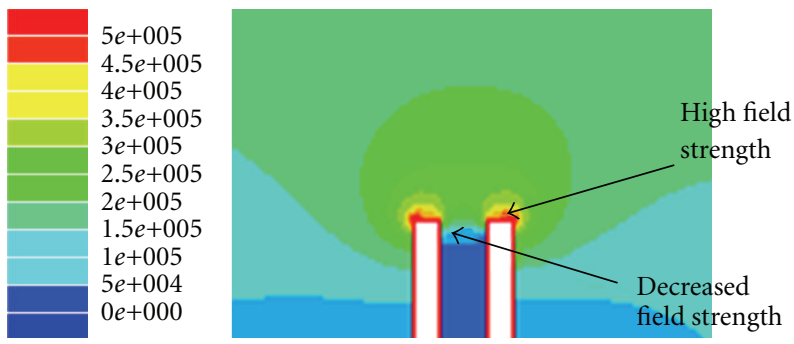

FIGURE 14: Enlargement of Figure 13.
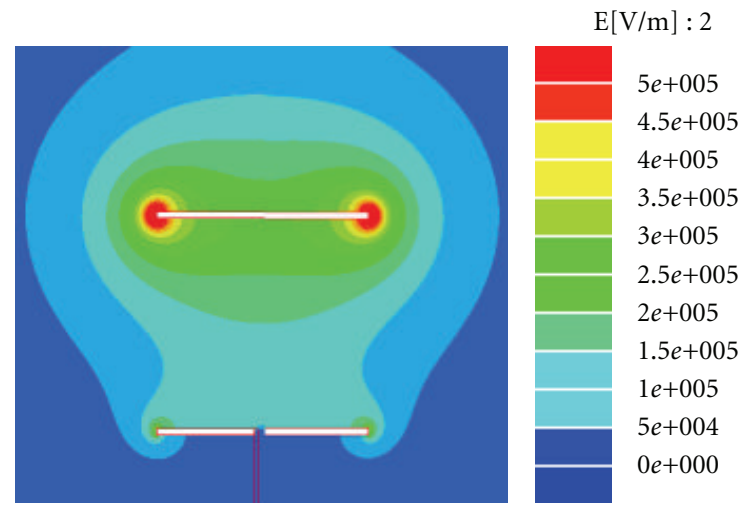

FIGURE 15: Comparison of bottom plates with (right) and without (left) a hole cut in.

area. However, this set up could not be used practically as there is no hole for the burner to protrude through. A mesh could be used with the burner below it but it was found experimentally that this disturbed the flow, often causing the flame to split into 2 or even 3 smaller flames as it passed through the mesh. This effect was amplified when a field was applied. There were even occasions when the flame jumped off the burner and settled on the mesh. While this provided a stable flame it was considered undesirable as the equivalence ratio could not be calculated as extra air was entrained into the flame from under the mesh.

Figure 15 shows the effect of cutting a hole in the bottom plate to allow the burner to fit through. The results show that the affect on the field is not significant. This was considered the best experimental set-up for analysis for the analysis of how an electric field influences a flame.

The field strength along the centre line of the plot can be shown for both results. This can be seen in Figure 16 .

The results from Figures 16 and 17 show that the affect on the field strength is only significant in the first $1-2 \mathrm{~mm}$ above the burner. Therefore cutting a hole in the bottom plate to allow the burner to protrude does not significantly alter the field characteristics.

Aerodynamically the bottom plate being made of a solid sheet will have an affect as additional air cannot be entrained from directly below. However, this affect should be small. The greater affect is from the electrode above the flame. If this was made from a solid sheet, the flow would be significantly

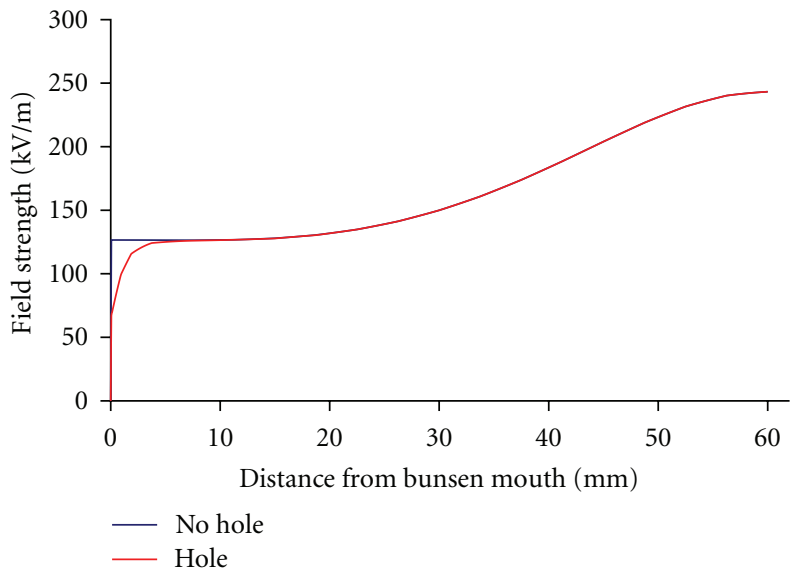

Figure 16: Comparison of the field strength with and without a hole in the bottom plate.

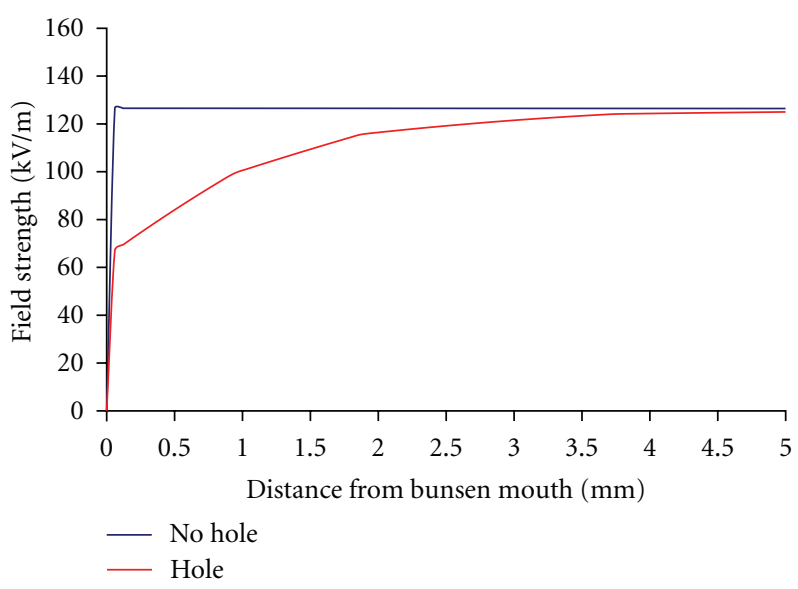

FIgURe 17: Enlargement of Figure 16.

altered. The best option was to use a mesh to avoid this aerodynamic disturbance (as well as heat being reflected back into the flame region).

\section{Conclusions}

In conclusion, results from many of the experiments in the literature cannot be compared as the field they have used is very different. Parallel plates produce the most uniform field.

\section{References}

[1] H. F. Calcote, "Mechanisms for the formation of ions in flames," Combustion and Flame, vol. 1, no. 4, pp. 385-403, 1957.

[2] M. Rickard, D. Dunn-Rankin, F. Weinberg, and F. Carleton, "Characterization of ionic wind velocity," Journal of Electrostatics, vol. 63, no. 6-10, pp. 711-716, 2005.

[3] E. Sher, G. Pinhasi, A. Pokryvailo, and R. Bar-On, "Extinction of pool flames by means of a DC electric field," Combustion and Flame, vol. 94, no. 3, pp. 244-252, 1993. 
[4] G. A. Gulyaev, G. A. Popkov, and Y. N. Shebeko, "Effect of a constant electrical field on combustion of a propane-butane mixture with air," Combustion, Explosion, and Shock Waves, vol. 21, no. 4, pp. 401-403, 1985.

[5] H. Calcote and R. Pease, "Electrical properties of flames. Burner flames in longitudinal electric fields," Industrial and Engineering Chemistry, vol. 43, pp. 2726-2731, 1951.

[6] H. F. Calcote and C. H. Berman, "Increased methane-air stability limits by a DC electric field," in Proceedings of the American Society of Mechanical Engineers, Petroleum Division (ASME PD '88), vol. 25, pp. 25-31, 1988.

[7] H. C. Jaggers and A. von Engel, "The effect of electric fields on the burning velocity of various flames," Combustion and Flame, vol. 16, no. 3, pp. 275-285, 1971.

[8] M. Saito, M. Arai, and T. Arai, "Control of soot emitted from acetylene diffusion flames by applying an electric field," Combustion and Flame, vol. 119, no. 3, pp. 356-366, 1999.

[9] K. Criner, A. Cessou, J. Louiche, and P. Vervisch, "Stabilization of turbulent lifted jet flames assisted by pulsed high voltage discharge," Combustion and Flame, vol. 144, no. 1-2, pp. 422 425, 2006.

[10] R. J. Heinsohn, D. Wulfhorst, and P. Becker, "The effects of an electric field on an opposed-jet diffusion flame," Combustion and Flame, vol. 11, no. 4, pp. 288-296, 1967.

[11] C. H. Berman, R. J. Gill, and H. F. Calcote, " $\mathrm{NO}_{x}$ reduction in flames stabilized by an electric field," in Proceedings of the American Society of Mechanical Engineers, Petroleum Division (ASME PD '91), vol. 33, pp. 71-75, January 1991.

[12] R. Noorani and R. Holmes, "Effects of electric fields on the blowoff limits of a methane-air flame," American Institute of Aeronautics and Astronautics, vol. 23, no. 9, p. 1432, 1985.

[13] D. Bradley and S. H. Nasser, "Electrical coronas and burner flame stability," Combustion and Flame, vol. 55, no. 1, pp. 53 $58,1984$.

[14] H. F. Calcote and C. H. Berman, "Increased methane-air stability limits by a DC electric field," in Proceedings of the American Society of Mechanical Engineers, Petroleum Division (ASME PD '89), vol. 25, pp. 25-31, January 1989.

[15] R. Noorani and R. Holmes, "Effects of electric fields on the blowoff limits of a methane-air flame," American Institute of Aeronautics and Astronautics, vol. 23, no. 9, pp. 14-32, 1985.

[16] K. Payne and F. Weinberg, "A preliminary investigation of field induced ion movement in flame gases and its applications," Proceedings of the Royal Society A, vol. 250, p. 316, 1959.

[17] Z. Yuan, U. Hegde, and G. Faeth, "Effects of electric fields on non-buoyant spherical diffusion flames," Combustion and Flame, vol. 124, no. 4, pp. 712-716, 2001.

[18] J. Lawton, P. Mayo, and F. Weinberg, "Electrical control of gas flows in combustion processes," Proceedings of the Royal Society A, vol. 303, p. 275, 1968.

[19] F. Weinberg, "Electrical intervention in the sooting of flames," in Proceedings of the NATO Workshop on Soot in Combustion Systems and its Toxic Properties, pp. 243-257, 1981.

[20] M. Saito, M. Sato, and K. Sawada, "Variation of flame shape and soot emission by applying electric field," Journal of Electrostatics, vol. 39, no. 4, pp. 305-311, 1997.

[21] H. Wager, "Soot formation in combustion," in Proceedings of the Plenary Lecture to 17th Symposium (International) on Combustion, vol. 3, the combustion Institute, Pittsburg, Pa, USA, 1979.

[22] Y. Mizutani, M. Fuchihata, and Y. Ohkura, "Pre-mixed laminarflames in a uniform magnetic field," Combustion and Flame, vol. 125, no. 1-2, pp. 1071-1073, 2001.
[23] R. Bowser and F. Weinberg, "Electrons and the emission of soot from flames," Nature, vol. 249, no. 5455, pp. 339-341, 1974.

[24] R. Bowser and F. Weinberg, "Chemi-ionisation during pyrolysis," Combustion and Flame, vol. 27, pp. 21-32, 1976.

[25] S. E. Pratsinis, "Flame synthesis of nanosize particles: precise control of particle size," Journal of Aerosol Science, vol. 27, no. 1, pp. S153-S154, 1996.

[26] A. Vatazhin, V. Likhter, V. Sepp, and V. Shulgin, "Electric field influence in nitrogen oxides emission in laminar diffusion flames," Journal of Aerosol Science, vol. 26, supplement 1, pp. 651-652, 1996.

[27] F. Weinberg, "Electrical intervention in the sooting of flames," in Proceedings of the NATO Workshop on Soot in Combustion Systems and its Toxic Properties, pp. 243-257, 1981.

[28] C. H. Berman, R. J. Gill, and H. F. Calcote, " $\mathrm{NO}_{x}$ reduction in flames stabilized by an electric field," in Proceedings of the American Society of Mechanical Engineers, Petroleum Division (ASME PD '91), vol. 33, pp. 71-75, January 1991.

[29] S. S. Sandhu and F. J. Weinberg, "Laser interferometric studies of the control of heat transfer from flame gases by electric fields," Combustion and Flame, vol. 25, pp. 321-334, 1975.

[30] S. M. Lee, C. S. Park, M. S. Cha, and S. H. Chung, "Effect of electric fields on the liftoff of nonpremixed turbulent jet flames," IEEE Transactions on Plasma Science, vol. 33, no. 5, pp. 1703-1709, 2005.

[31] R. J. Bowser and F. J. Weinberg, "The effect of direct electric fields on normal burning velocity," Combustion and Flame, vol. 18, no. 2, pp. 296-300, 1972.

[32] H. C. Jaggers, R. J. Bowser, F. J. Weinberg, R. J. Bowser, S. S. Sandhu, and F. J. Weinberg, "The effect of electric fields on burning velocity," Combustion and Flame, vol. 19, no. 1, pp. 135-136, 1972.

[33] C. Christopoulos, An Introduction to Applied Electromagnetism, John Wiley and Sons, Chichester, UK, 1990.

[34] "Ansoft Maxwell 2DElectromagnetic-field simulation," Ansoft Corporation, Pittsberg, Pa, 2006, http://www.ansoft.com/proproducts/em/max $2 \mathrm{~d}$.

[35] D. Meeker, "Manual for finite element method magnetics," 2007, http://femm.foster-miller.net/wiki/Documentation.

[36] F. Cecelja, M. Bordovsky, and W. Balachandran, "Lithium niobate sensor for measurement of DC electric fields," IEEE Transactions on Instrumentation and Measurement, vol. 50, no. 2, pp. 465-469, 2001.

[37] J. Lawton and F. Weinberg, Electrical Aspects of Combustion, Clarendon Press, Oxford, UK, 1969.

[38] Fluent .

[39] P. Glarborg, R. Kee, J. Grear, and J. Miller, "A fortran program for modelling well stirred reactors," Sandia National Laboratories Report SAND86-8209, 1986.

[40] R. Kee, J. Grear, M. Smooke, and J. Miller, “A fortran program for modelling steady laminar one dimensional premixed flames," Sandia National Laboratories Report SAND85-8240, 1985.

[41] T. Pedersen, Ionic structure of methane flames, Ph.D. thesis, Iowa State University, Ames, Iowa, USA, 1991.

[42] T. Pedersen and R. Brown, "Simulation of electric field effects in premixed methane flames," Combustion and Flame, vol. 94, no. 4, pp. 433-448, 1993.

[43] A. M. Starik and N. S. Titova, "Kinetics of ion formation in the volumetric reaction of methane with air," Combustion, Explosion and Shock Waves, vol. 38, no. 3, pp. 253-268, 2002. 
[44] J. Hu, B. Rivin, and E. Sher, "The effect of an electric field on the shape of co-flowing and candle-type methane-air flames," Experimental Thermal and Fluid Science, vol. 21, no. 1-3, pp. 124-133, 2000.

[45] A. B. Fialkov, "Investigations on ions in flames," Progress in Energy and Combustion Science, vol. 23, no. 5-6, pp. 399-528, 1997.

[46] J. Lawton and F. Weinberg, "Maximum ion current from flames and the maximum practical effects of applied electric fields," Proceedings of the Royal Society A, vol. 277, p. 469, 1964.

[47] G. A. Gulyaev and G. A. Popkov, "Effect of inert gas dilution on electrical potential distribution in a propanebutane flame," Combustion, Explosion, and Shock Waves, vol. 25, no. 5, pp. 552-554, 1990.

[48] L. A. Rosocha, Y. Kim, G. K. Anderson, J. O. Lee, and S. Abbate, "Decomposition of ethane in atmospheric-pressure dielectricbarrier discharges: experiments," IEEE Transactions on Plasma Science, vol. 34, no. 6, pp. 2526-2531, 2006.

[49] E. Sher, A. Pokryvailo, E. Jacobson, and M. Mond, "Extinction of flames in a nonuniform electric field," Combustion Science and Technology, vol. 87, no. 1-6, pp. 59-67, 1993.

[50] J. E. Mitchell and F. J. Wright, "Effects in diffusion flames by radial electric fields," Combustion and Flame, vol. 13, no. 4, pp. 413-418, 1969.

[51] H. F. Calcote, D. B. Olson, and D. G. Keil, "Are ions important in soot formation?” Energy and Fuels, vol. 2, no. 4, pp. 494504, 1988.

[52] G. A. Gulyaev, G. A. Popkov, and Y. N. Shebeko, "Effect of a constant electric field on self-ignition temperature of organic materials in air," Combustion, Explosion, and Shock Waves, vol. 21, no. 4, pp. 403-404, 1985.

[53] A. F. Panteleev, G. A. Popkov, S. G. Tsarichenko, and Y. N. Shebeko, "Effect of an electric field on the flame propagation over a solid material surface," Combustion, Explosion, and Shock Waves, vol. 28, no. 3, pp. 244-246, 1992.

[54] A. F. Panteleev, G. A. Popkov, and Y. N. Shebeko, "Effect of an electric field on the vaporization and burning of combustible liquids," Combustion, Explosion, and Shock Waves, vol. 28, no. 3, pp. 242-244, 1992.

[55] J. Hu, B. Rivin, and E. Sher, "Experimental and numerical study of the effect of an electric field on a Bunsen-type flame," Israel Journal of Chemistry, vol. 39, no. 1, pp. 87-96, 1999.

[56] F. L. Jones, P. M. Becker, and R. J. Heinsohn, "A mathematical model of the opposed-jet diffusion flame: effect of an electric field on concentration and temperature profiles," Combustion and Flame, vol. 19, no. 3, pp. 351-362, 1972.

[57] M. Smook, P. Lin, J. Lam, and M. Long, "Computational and experimental study of a laminar axisymmetric methane air diffusion flame," in Proceedings of the 23rd Symposium (International) on Combustion, p. 575, The Combustion Institute, Pittsburgh, Pa, USA, 1990.

[58] S. D. Marcum and B. N. Ganguly, "Electric-field-induced flame speed modification," Combustion and Flame, vol. 143, no. 1-2, pp. 27-36, 2005.

[59] R. J. Heinsohn, C. F. Wilhelm, and P. M. Becker, "Effect of electric fields on ducted diffusion flames," Combustion and Flame, vol. 14, no. 3, pp. 341-349, 1970.

[60] M. Kono, K. IInuma, and Kumagai, "The effect of DC to 10 $\mathrm{MHz}$ electric field on flame luminosity and carbon formation," in Proceedings of the 18th Symposium on Combustion, $\mathrm{p}$. 1167, The Combustion Institute, Pittsberg, Pa, USA, 1981.
[61] M. Kono, F. B. Carleton, A. R. Jones, and F. J. Weinberg, "The effect of nonsteady electric fields on sooting flames," Combustion and Flame, vol. 78, no. 3-4, pp. 357-364, 1989.

[62] G. A. Gulyaev, G. A. Popkov, and Y. N. Shebeko, "Synergism effects in combined action of electric field and inert diluent on gas-phase flames," Combustion, Explosion, and Shock Waves, vol. 23, no. 2, pp. 170-172, 1987.

[63] A. F. Panteleev, G. A. Popkov, Y. N. Shebeko, and S. G. Tsarichenko, "Effect of ac field on the limiting blow-off flow-rate value for a diffusion propane-hydrogen flame," Combustion, Explosion, and Shock Waves, vol. 29, no. 1, pp. 32-33, 1993.

[64] G. A. Gulyaev, G. A. Popkov, Y. N. Shebeko, and A. P. Korolenok, "Joint action of an inert diluent and electric field on gas-phase flames," Combustion, Explosion, and Shock Waves, vol. 24, no. 6, pp. 700-702, 1988.

[65] F. Weinberg, "Electrical aspects of aerosol formation and control," Proceedings of the Royal Society A, vol. 307, p. 195, 1968.

[66] E. Place and F. Weinberg, "The nucleation of flame carbon by ions and the effect of electric fields," in Proceedings of the 11th Symposium on Combustion, p. 245, The Combustion Institute, Pittsberg, Pa, USA, 1967.

[67] A. F. Panteleev, G. A. Popkov, Y. N. Shebeko, S. G. Tsarichenko, and V. I. Gorshkov, "Effect of an electric field on concentration limits for propane flame propagation in air," Combustion, Explosion, and Shock Waves, vol. 27, no. 1, pp. 22-24, 1991.

[68] F. Carleton, D. Dunn-Rankin, and F. Weinberg, "Optics of small diffusion flames in microgravity," Symposium (International) on Combustion, vol. 2, pp. 2567-2572, 1998.

[69] F. B. Carleton and F. J. Weinberg, "Electric field-induced flame convection in the absence of gravity," Nature, vol. 330, no. 6149, pp. 635-636, 1987.

[70] R. G. Fowler and S. J. B. Corrigan, "Burning-wave speed enhancement by electric fields," Physics of Fluids, vol. 9, no. 10, pp. 2073-2074, 1966.

[71] A. Y. Starikovskii, "Plasma supported combustion," in Proceedings of the Combustion Institute, pp. 2405-2417, 2005.

[72] S. A. Bozhenkov, S. M. Starikovskaia, and A. Y. Starikovskii, "Nanosecond gas discharge ignition of $\mathrm{H}_{2}^{-}$and $\mathrm{CH}_{4}^{-}$containing mixtures," Combustion and Flame, vol. 133, no. 1-2, pp. 133-146, 2003.

[73] E. Place and F. Weinberg, "Electrical control of flame carbon," Proceedings of the Royal Society A, vol. 289, p. 192, 1965.

[74] P. Mayo and F. Weinberg, "On the size, charge and number rate if formation of carbon particles in flames subjected to electric fields," Proceedings of the Royal Society A, vol. 319, p. 351, 1970. 

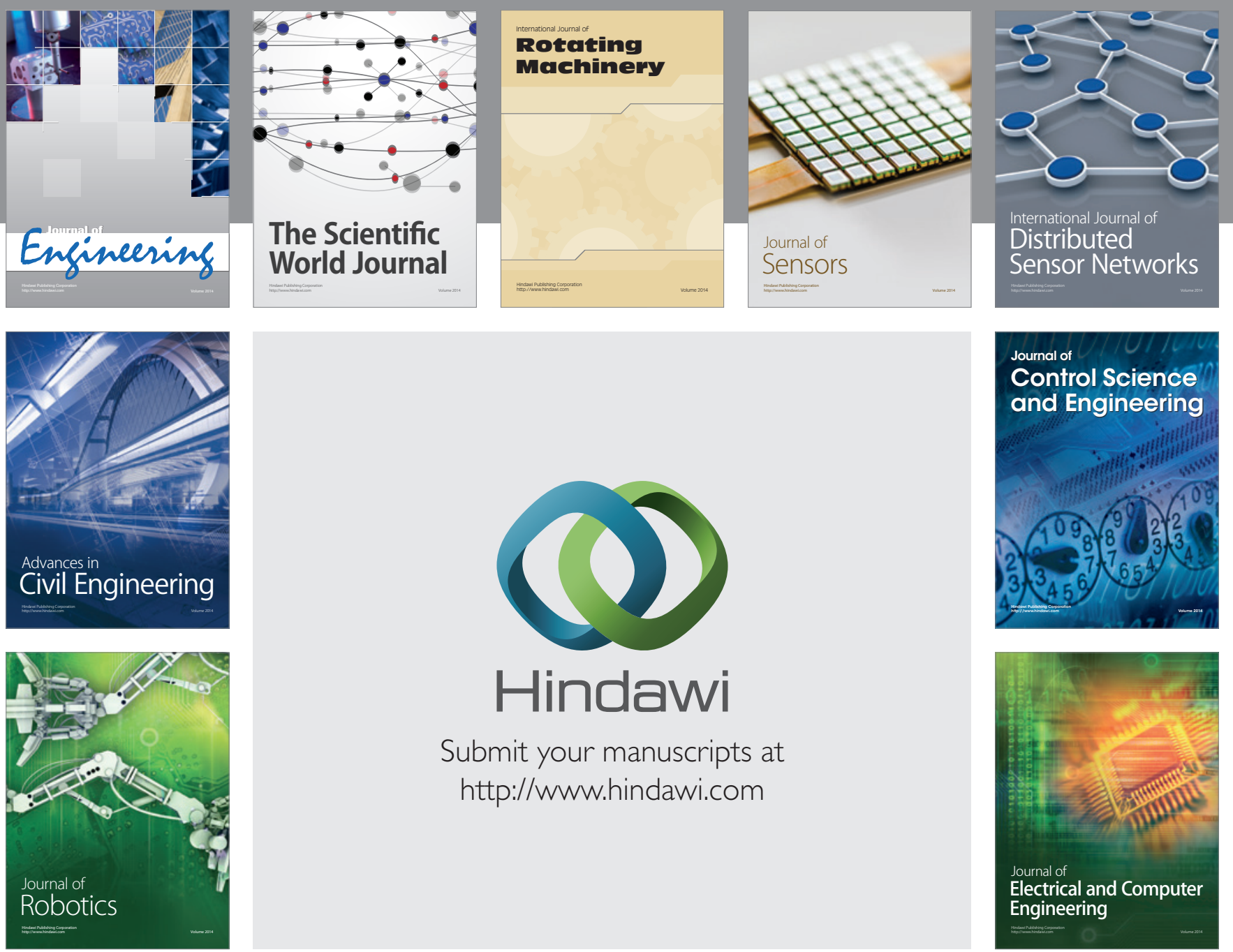

Submit your manuscripts at

http://www.hindawi.com
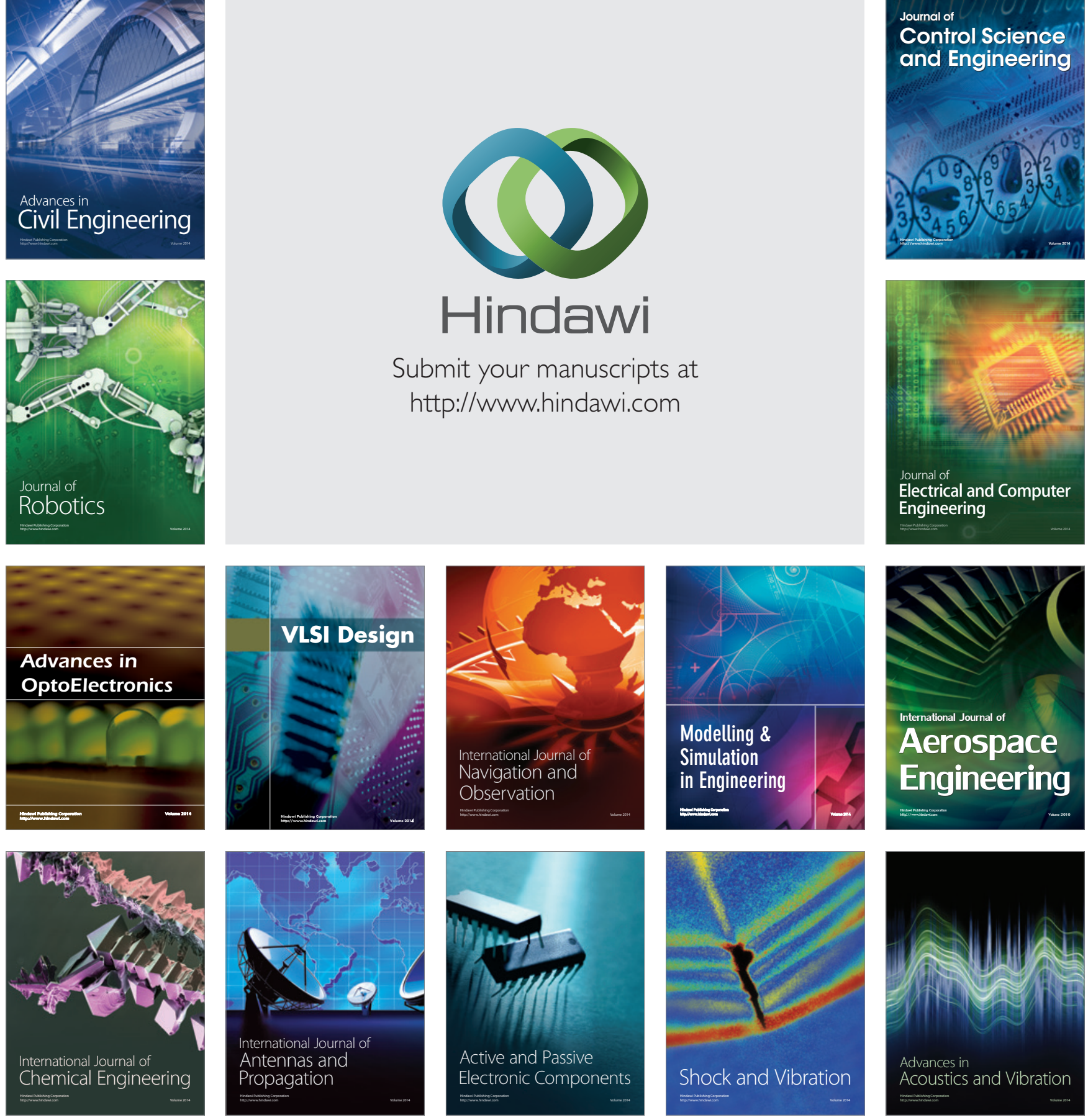